\title{
Doppler SODAR observations of the temperature structure parameter during monsoon season over a tropical rural station, Gadanki
}

\author{
M Shravan Kumar ${ }^{1}$, V K Anandan ${ }^{2, *}$, Amit Kesarkar ${ }^{1}$ and P Narasimha Reddy ${ }^{3}$ \\ ${ }^{1}$ National Atmospheric Research Laboratory, Gadanki 517 112, India. \\ ${ }^{2}$ RDA, ISTRAC, Indian Space Research Organisation, Bangalore 560 058, India. \\ ${ }^{3}$ Department of Physics, Sri Venkateswara University, Tirupati 517 502, India. \\ *e-mail: anandanvk@hotmail.com
}

\begin{abstract}
Doppler SODAR (Sound Detection and Ranging) measurements over a tropical Indian station at National Atmospheric Research Laboratory (NARL), Gadanki $\left(13.5^{\circ} \mathrm{N}, 79.2^{\circ} \mathrm{E}\right.$ ) during two consecutive monsoon seasons, 2007 and 2008, are investigated to study the influence of mechanically generated turbulence on temperature structure parameter $\left(\mathrm{C}_{\mathrm{T}}^{2}\right)$ in the convective boundary layer. Increase in the $\mathrm{C}_{\mathrm{T}}^{2}$ is observed after the arrival of monsoon for both seasons. Contribution of vertical wind shear in horizontal wind component to $\mathrm{C}_{\mathrm{T}}^{2}$ due to zonal winds is responsible for the increase observed in the temperature structure parameter which is inferred from the results obtained. $\mathrm{C}_{\mathrm{T}}^{2}$ is found to be increased by an order of 2 in both the lower and upper altitudes, respectively. Magnitude of wind speed is reported to be doubled with the arrival of monsoon. It is also observed that, southwest monsoon wind modulates the day-to-day variations of wind pattern over this station during the onset phase of monsoon season. The lower variability observed at lower height is attributed to the complex topography surrounding this region.
\end{abstract}

\section{Introduction}

Sound Detection and Ranging (SODAR) is a widely used remote sensing instrument in the atmospheric boundary layer (ABL) studies. It is also found useful for the observation of turbulence in the atmosphere over regional scale. It is well known that the intensity of the acoustic backscatter signal from a monostatic Doppler SODAR varies due to the temperature fluctuations in the scattering volume and is proportional to the temperature structure parameter $\mathrm{C}_{\mathrm{T}}^{2}$ in the $\mathrm{ABL}$. Measurement of the $\mathrm{C}_{\mathrm{T}}^{2}$ is found very useful to many investigators for optical tracking and in the turbulence studies (Tsvang 1963; Koprov 1965; Warner 1972; Bufton 1973; Coulman 1973; Warhaft 1973; Caughey and Readings 1974; Weill et al 1976). $\mathrm{C}_{\mathrm{T}}^{2}$ can be measured by a well cali- brated Doppler SODAR and was proved earlier by many researchers. Therefore, it is popularly used as an indicator of turbulence (Neff 1975; Asimakopoulos et al 1976; Kaimal et al 1976; Gaynor 1977; Caughey et al 1978; Haugen and Kaimal 1978; Coulter and Wesely 1980; Weill et al 1980; Moulsley et al 1981; Dubosclard 1982; Helmis et al 2000). Cuijpers and Kohsiek (1989) have shown that vertical profile of $\mathrm{C}_{\mathrm{T}}^{2}$ depends on the geostrophic wind speed in the nocturnal boundary layer. During night in the first few hours with moderate wind speeds and later with high wind speeds, $\mathrm{C}_{\mathrm{T}}^{2}$ is found to be large at the surface and becomes small as it reaches top of the NBL. The high geostrophic wind leads to large value of $\mathrm{C}_{\mathrm{T}}^{2}$ at three quarters of boundary layer height. Derr and Little (1970) have shown that temperature structure parameter has a great importance in

Keywords. Temperature structure parameter; turbulence; Doppler SODAR; winds and monsoon; atmospheric science; remote sensing and monsoons. 

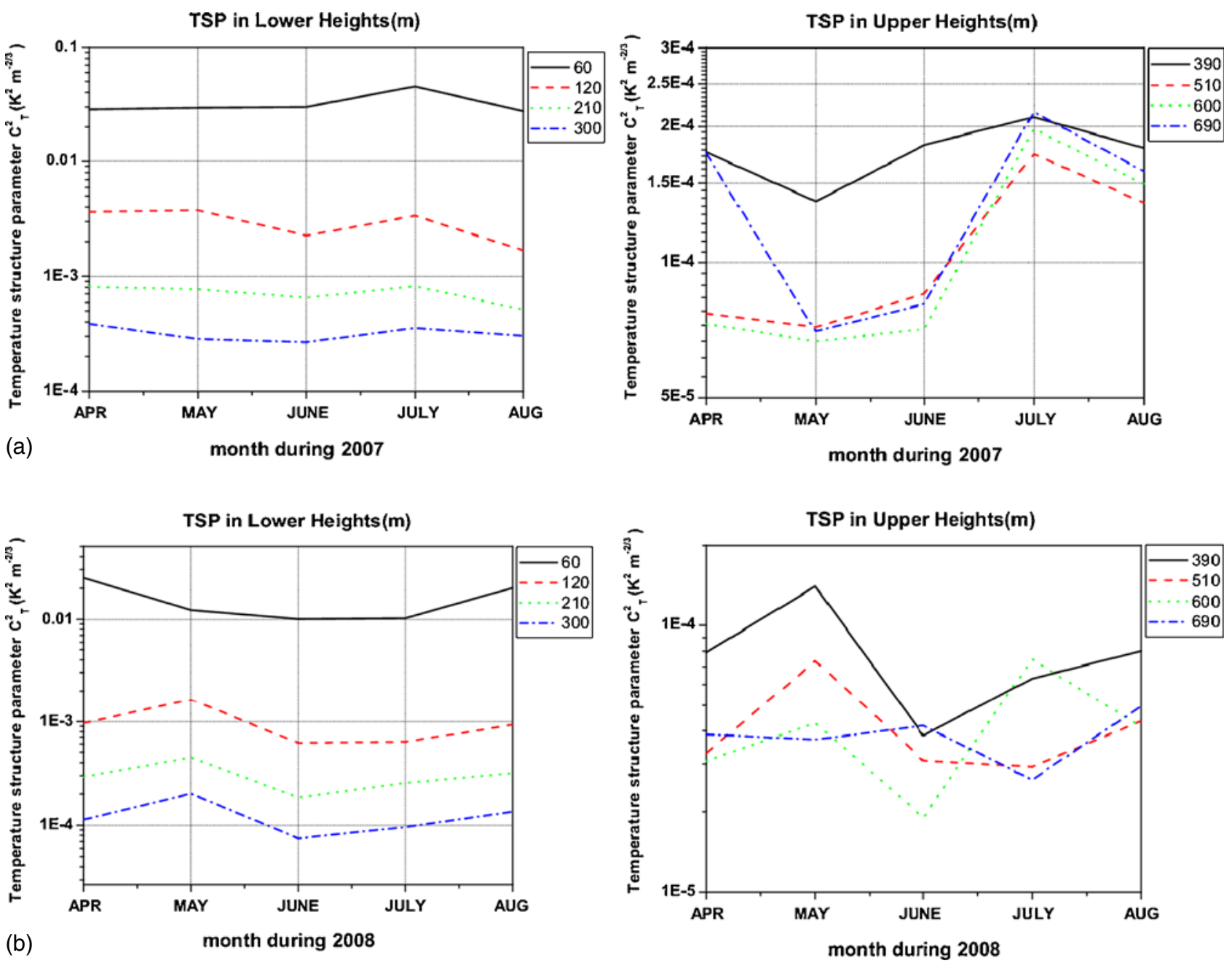

Figure 1. Monthly variations of $\mathrm{C}_{\mathrm{T}}^{2}$ at various height levels during (a) 2007 and (b) 2008 .

cloud physics for an understanding of the dynamical characteristics of monsoon clouds. Further, the study by Singhal et al (1982) has reported high values of $\mathrm{C}_{\mathrm{T}}^{2}$ during monsoon season in unstable conditions over New Delhi. Therefore, it is important to know that how values of $\mathrm{C}_{\mathrm{T}}^{2}$ vary during the different phases of the monsoon. Especially during the onset phase of the monsoon season an increase in the lower level turbulence is reported.

Turbulence in the atmosphere is generated by two mechanisms - buoyancy, mechanical or by both. The results of the investigations discussed above have made us curious to understand about the contribution of mechanically driven turbulence (wind shear) to the structure parameter of temperature over a tropical latitude station in a complex terrain environment. For this investigation we have used Doppler SODAR measurements for two monsoon seasons, 2007 and 2008. SODAR observations from April to July are considered for the present study to investigate how the transition in the wind and temperature structure parameters takes place during the transition from summer to monsoon season. The detailed description of the NARL SODAR system and the methodology used for calculating the temperature structure parameter are given in section 2. The discussions on the various results pertaining to the contribution of mechanically driven turbulence to the $\mathrm{C}_{\mathrm{T}}^{2}$ are given in section 3 . The results are summarized in section 4 .

\section{System description and methodology}

NARL Gadanki, a tropical rural station is located at $13.5^{\circ} \mathrm{N}, 79.2^{\circ} \mathrm{E}$ in the southern part of India. It is situated at $370 \mathrm{~m}$ above the mean sea level and surrounded by hillocks varying from $200-300 \mathrm{~m}$ in the radius of $1 \mathrm{~km}$. Hill's altitude also extended to $700 \mathrm{~m}$ in the radial distance of $10 \mathrm{~km}$. This station is located $80 \mathrm{~km}$ away, in radial distance from the east coast of Indian peninsula. SODAR has 

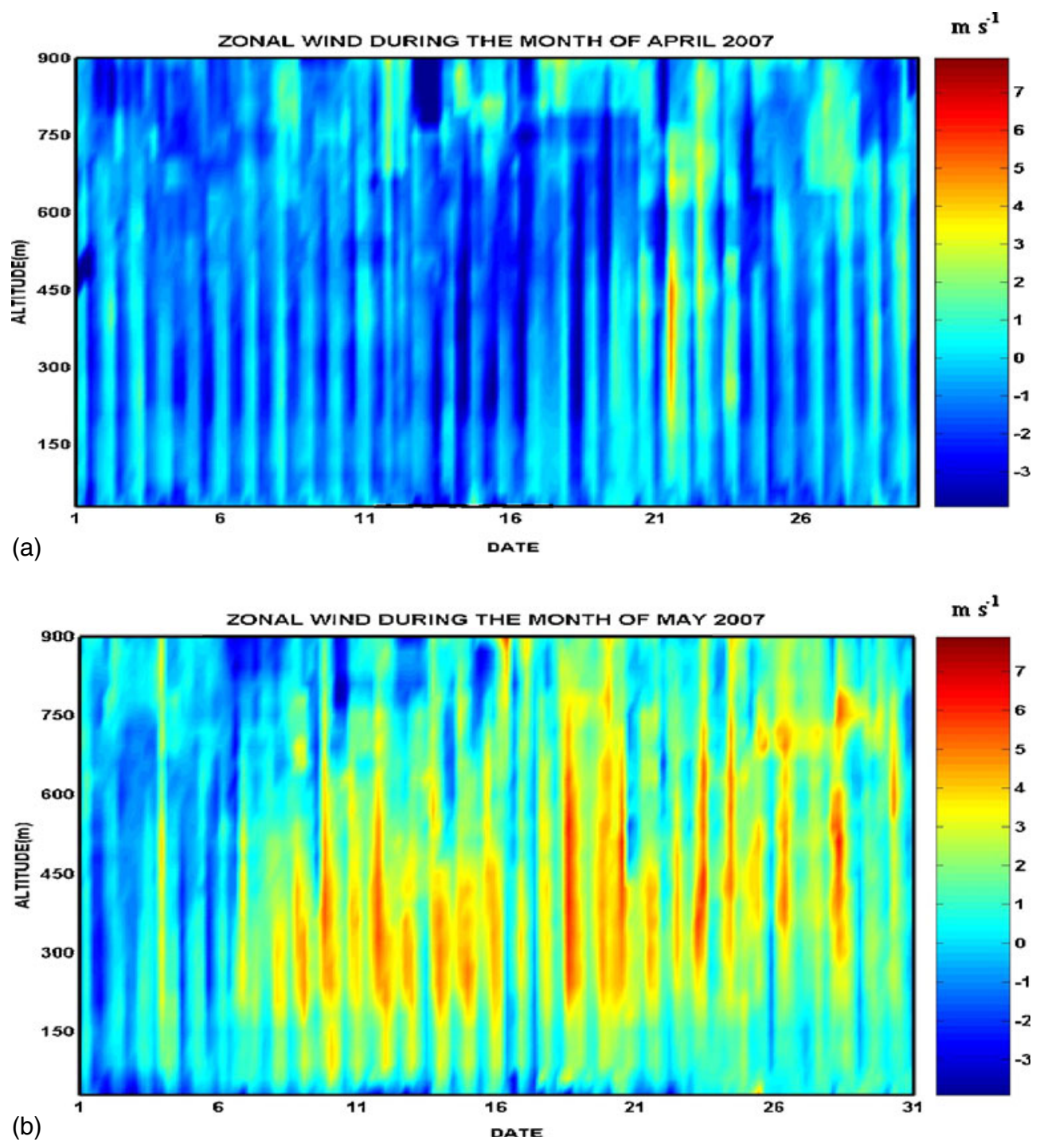

Figure 2. Six hourly averaged zonal wind plots for the months of (a) April, (b) May, (c) June, and (d) July for 2007.

been in continuous operation since January 2007 onwards. Anandan et al (2008) have described the technical specifications of the NARL SODAR system, signal processing, data quality control and preliminary validation of the system data products. This SODAR measures the radial velocities along three beams by analyzing the observed Doppler shifted signals adopting Doppler beam swinging technique. Such type of configuration enables measurement of horizontal (zonal, meridional) and vertical (zenith) components of the wind speed. The system can measure winds from ground up to $1 \mathrm{~km}$ (in favourable conditions up to $1.3 \mathrm{~km}$ ). However, in this paper we have considered SODAR data height up to $1 \mathrm{~km}$ for consistency. Since Doppler SODAR utilizes backscattered acoustic signals, the pulse width of the acoustic emission sound needs to be longer and stronger for better detection. Simultaneously, the height resolution needs to be main- tained based on the study requirements as increase in pulse width will lead to coarser height resolution. In the lower atmosphere, for turbulence studies higher height resolution is important. Therefore, we are operating the SODAR with a frequency of $1800 \mathrm{~Hz}$, with a pulse length of $180 \mathrm{~ms}$ which results into vertical resolution of $30 \mathrm{~m}$. The back-scattered signal depends upon the turbulent and wind inhomogeneities present in the sampling area of the volume. Each beam takes 9 seconds to derive the velocity with altitude ranging from 30-1500 m with an interval of $30 \mathrm{~m}$. Moments computed from intervals with at least $80 \%$ of well distributed good data points have been taken for the analysis. The radial wind velocities have been used to calculate the zonal, meridional and vertical components of wind after passing through the quality check. Each vector wind profile is obtained for every 27 seconds to have high temporal resolution 

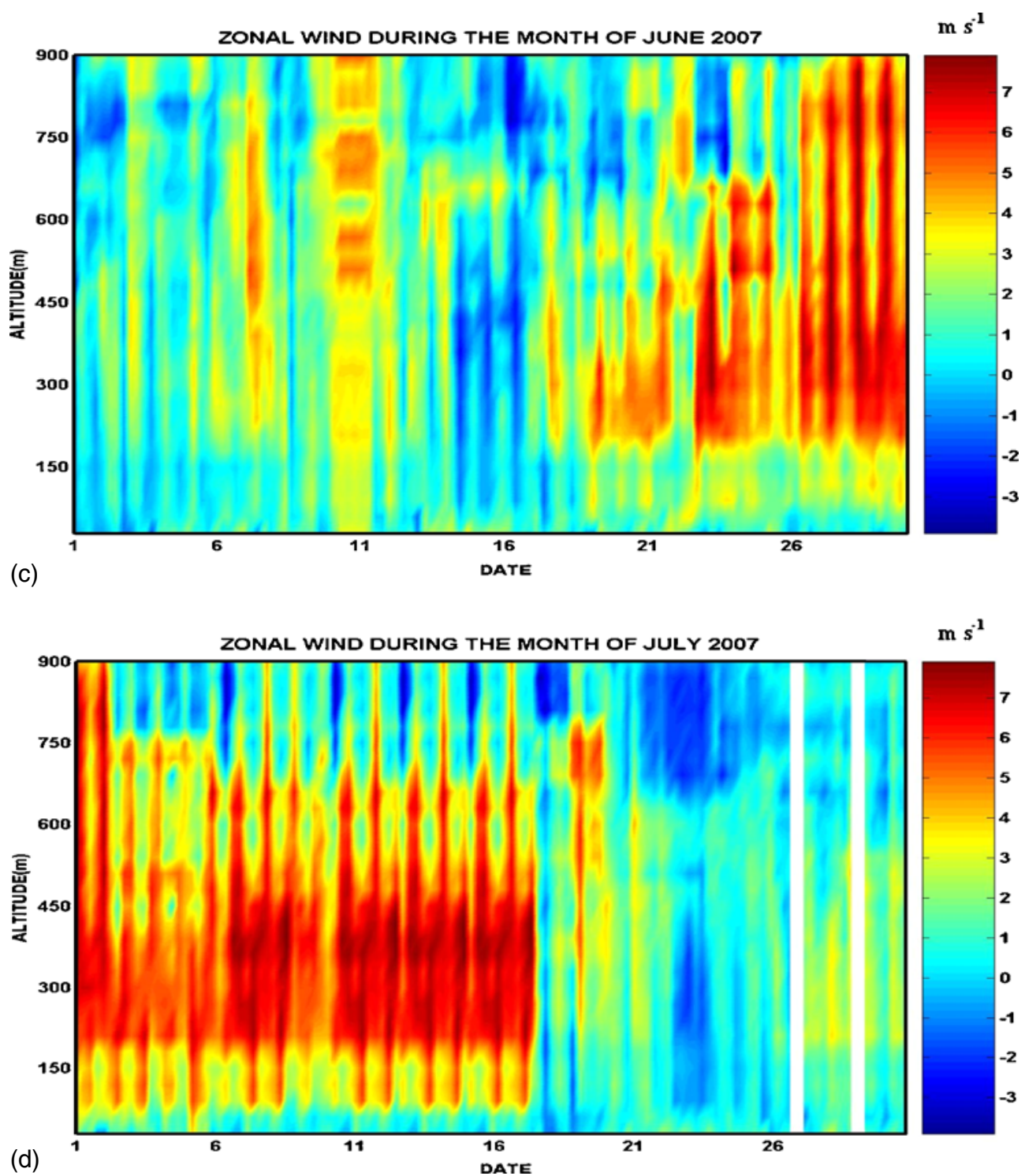

Figure 2. (Continued)

for different atmospheric studies. Received power in the zenith beam only is taken for deriving the temperature structure measurements.

\section{$2.1 C_{T}^{2}$ methodology}

The intensity of the acoustic backscatter signal from a monostatic Doppler SODAR due to the temperature fluctuations in the scattering volume is proportional to the $\mathrm{C}_{\mathrm{T}}^{2}$ in the $\mathrm{ABL}$. Thus $\mathrm{C}_{\mathrm{T}}^{2}$ is calculated from the SODAR equation. The monostatic SODAR equation is given as:

$$
P(r)=P_{t} \cdot A e \cdot C \cdot \tau \cdot \sigma \cdot \alpha / 2(r \cdot r)
$$

(Thomson et al 1978; Coulter and Wesely 1980; Dubosclard 1982; Coulter 1990; Helmis et al 2000 and Little 1969), where $P(r)$ is acoustic power received, $P_{t}$ is the acoustic power transmitted, $A_{e}$ is the effective area of the receiving antenna, $r$ is the range, $\alpha$ is the attenuation of the acoustic wave along the path, $\sigma$ is the cross-section of the scattering volume, $\tau$ is the transmitted pulse width and $C$ is the speed of sound. For homogeneous and isotropic turbulence, $\sigma$ can be written as:

$$
\sigma=0.00753 \cdot \lambda^{-1 / 3} \cdot \mathrm{C}_{\mathrm{T}}^{2} \cdot r \cdot T^{-2},
$$

where $\lambda$ is the acoustic wave length, $T$ is the mean temperature and $\mathrm{C}_{\mathrm{T}}^{2}$ the temperature structure parameter. Assuming a constant attenuation coefficient in the range of interest, from equations (1) and (2) it follows that:

$$
\begin{aligned}
\mathrm{C}_{\mathrm{T}}^{2}(r)= & 265.5\left[P(r) \cdot r \cdot r \cdot T \cdot T \cdot \lambda^{-1 / 3}\right] \\
& / P_{t} \cdot A e \cdot C \cdot \tau \cdot \sigma \cdot \alpha .
\end{aligned}
$$

Efficiency of the antenna system for converting the electrical power to acoustic power and acoustic 


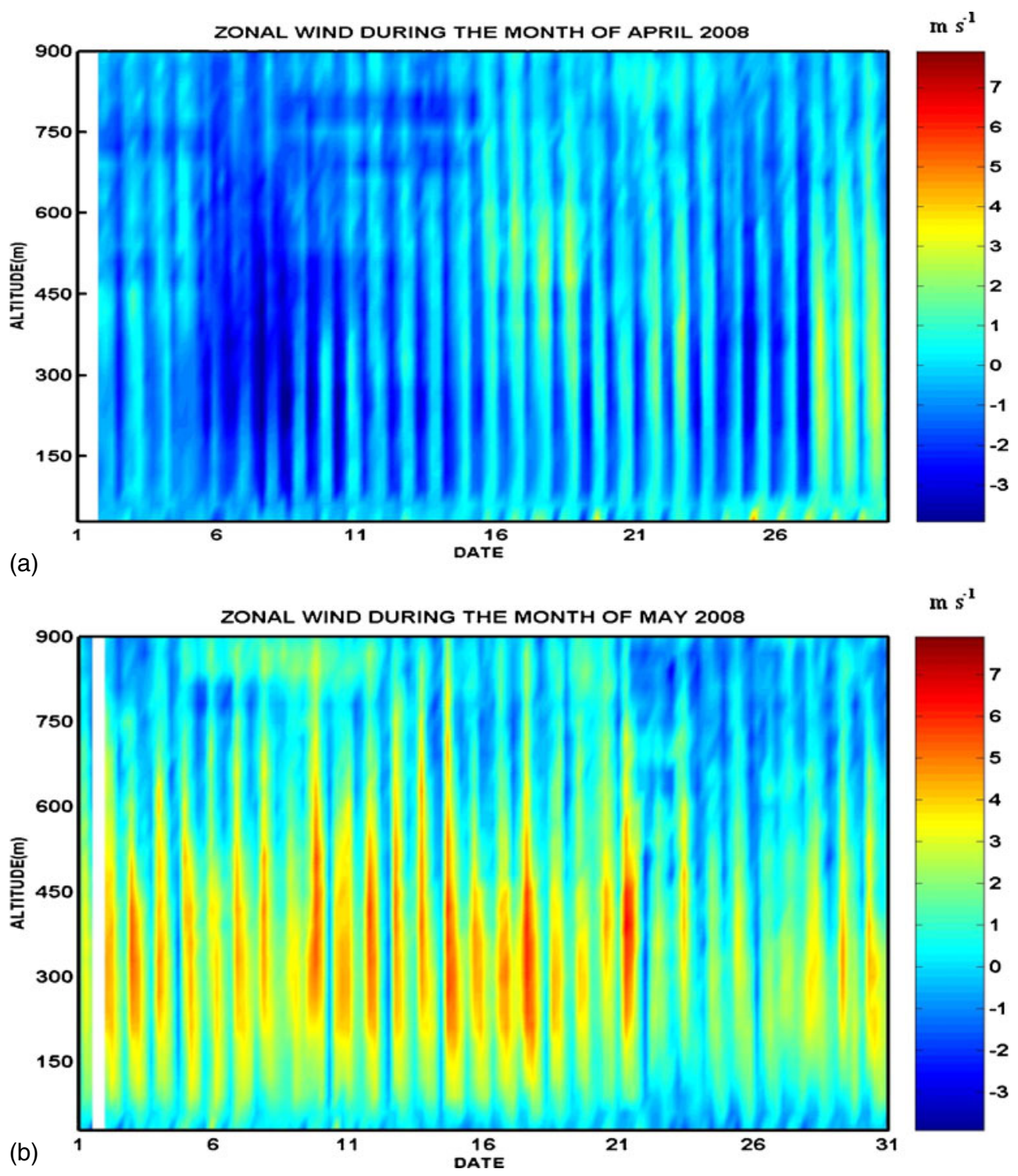

Figure 3. Six hourly averaged zonal wind plots for the months of (a) April, (b) May, (c) June, and (d) July for 2008.

electrical power is about $50 \%$. Uncertainties in the estimates of $\mathrm{C}_{\mathrm{T}}^{2}$ also arise from variations in the distribution of scatters, but these are considered to be less and are ignored (Haugen and Kaimal 1978). Temperature data is taken from regular GPS sonde launches from the laboratory.

\section{Results and discussion}

Figure $1(\mathrm{a}, \mathrm{b})$ shows the variations in the $\mathrm{C}_{\mathrm{T}}^{2}$ for both the monsoon seasons, 2007 and 2008. Lower and higher altitude regions have been separated to present the variations in detail. It is observed that $\mathrm{C}_{\mathrm{T}}^{2}$ decreases in magnitude with the increase in height for all the range levels. Lower range levels $(60-300 \mathrm{~m})$ show large variations in magnitude with respect to height whereas higher altitudes (500-690 m) have a constant trend with fewer variations in magnitude. $\mathrm{C}_{\mathrm{T}}^{2}$ is found to be increased by an order of 2 in both the lower and upper altitudes. However, comparatively there are variations in the $\mathrm{C}_{\mathrm{T}}^{2}$ profile for both the seasons, 2007 and 2008. There is a significant increase in $\mathrm{C}_{\mathrm{T}}^{2}$ from June to July in 2007 at higher altitudes, whereas such interesting trend is not observed in 2008. This is due to the change in background synoptic wind conditions during the observation period. Arrival of south-west (SW) monsoon over our station is earlier in 2008 than in 2007 as reported by India Meteorological Department (IMD). Onset of SW monsoon over Gadanki is around 13 June 2007 whereas during 2008 it is on 2 June. During 2007, peak in the $\mathrm{C}_{\mathrm{T}}^{2}$ magnitude is observed in July and 


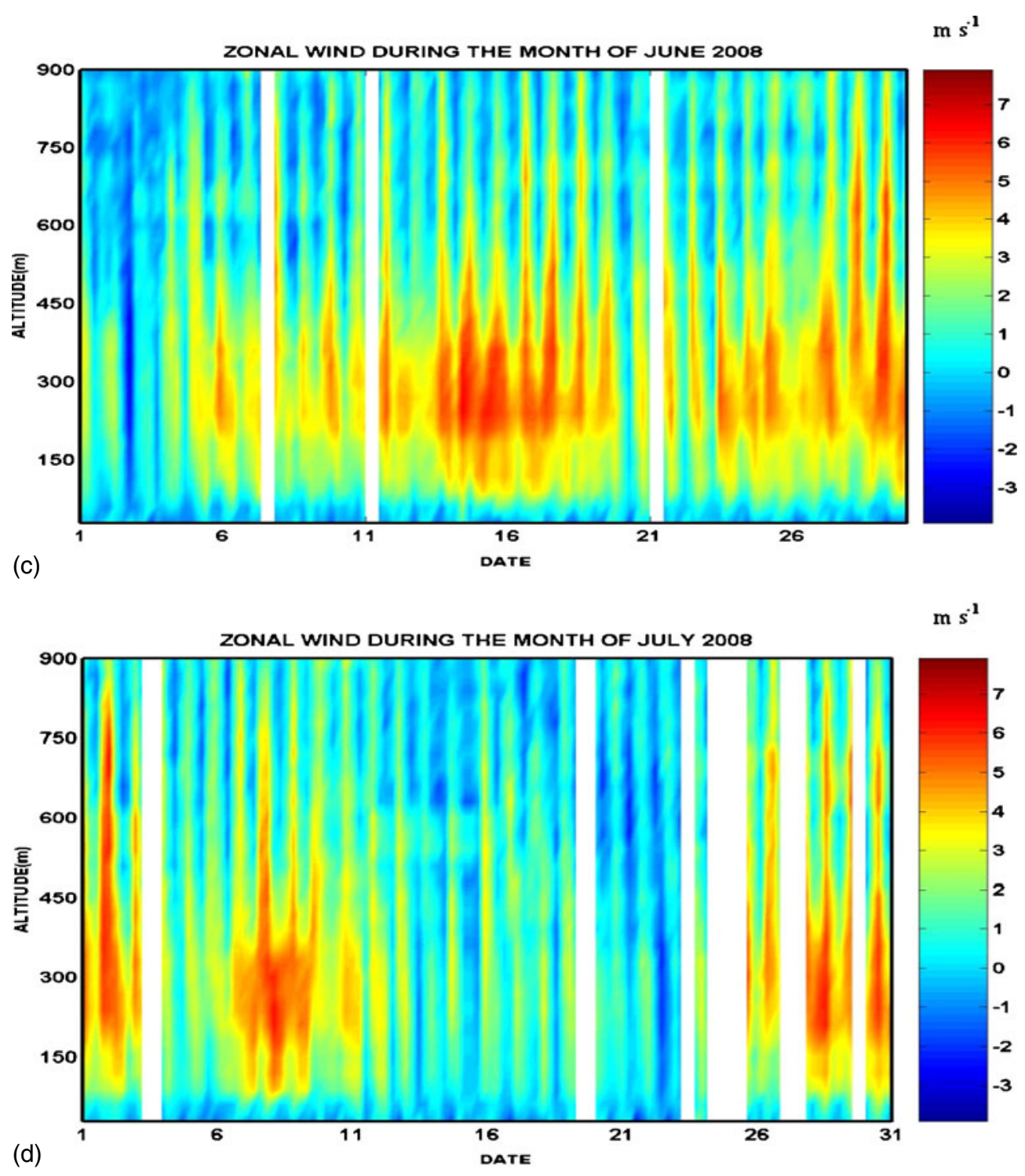

Figure 3. (Continued)

for 2008 it is in May. It is seen that the higher temperatures prevailing over landmasses lead to moderate values of $\mathrm{C}_{\mathrm{T}}^{2}$ during the pre-monsoon months only due to buoyancy, however, after the arrival of southwest monsoon over Indian subcontinent, increase in wind shear leads to the increase in the values of $\mathrm{C}_{\mathrm{T}}^{2}$ in the monsoon season. It is found that $\mathrm{C}_{\mathrm{T}}^{2}$ is large in the surface layer and it decreases with the increase in altitude. $\mathrm{C}_{\mathrm{T}}^{2}$ value shows decreasing trend from April to May during 2007 and increase after the arrival of monsoon in June and July. Increase in the zonal wind speed for 2007 is observed in June. In 2008, increase in $C_{T}^{2}$ is observed during May because increase in zonal wind speed is also observed during this month. Hence, mechanical turbulence is the possible cause for the increase in $\mathrm{C}_{\mathrm{T}}^{2}$ parameter.
Figure 2(a-d) represents the time height crosssections of day-to-day variations in the zonal wind component during April-July in 2007. Of particular interest is the evidence of increase in wind speed at the end of June. During summer months (April and May) winds are very calm and light. Strong westerly winds $>8 \mathrm{~ms}^{-1}$ are observed after the arrival of southwest monsoon season. Figure $3(\mathrm{a}-\mathrm{d})$ presents the time height cross-sections of day-to-day variations in the zonal wind component during April-July in 2008. Increase in wind speed is observed during day time in May 2008. The month of June shows fewer variations in the day-day pattern of the wind flows. During the initial phase of the monsoon, this day-to-day variations of zonal wind component is reduced or masked. An increase in the wind speed is observed during both day and 

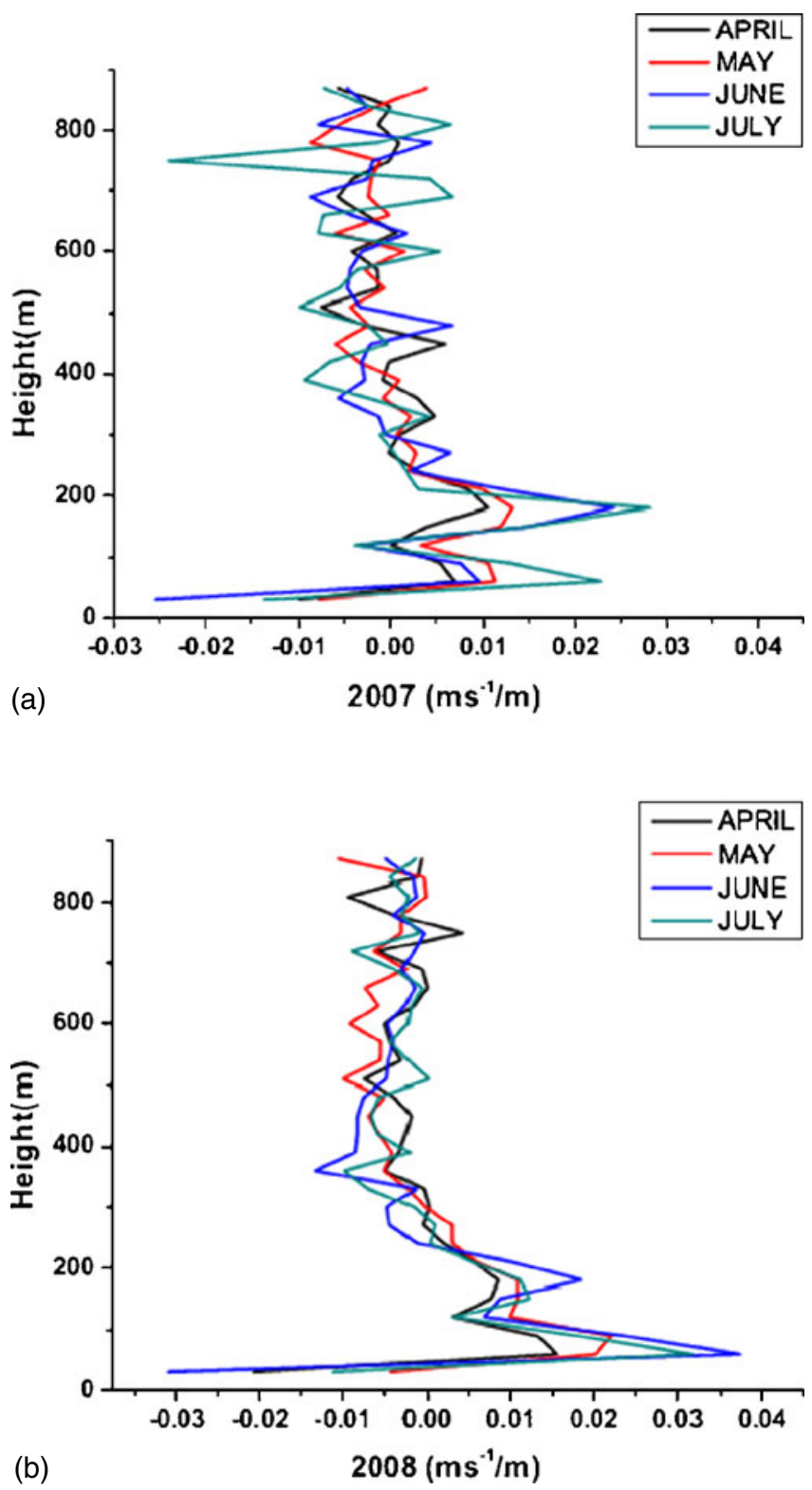

Figure 4. Monthly averaged vertical wind shear in horizontal wind during (a) 2007 and (b) 2008.

night, whereas during summer months an increase in wind speed is observed only during day time. This increase in the wind speed is responsible for the mechanically driven turbulence. This is generated by the zonal wind and is observed more in the upper heights. These observations were taken during unstable conditions of the CBL where buoyant effect is always present. During the months of April and May, turbulence present is mainly due to buoyancy whereas after the arrival of monsoon increase in turbulence is observed due to the addition of mechanically generated turbulence to buoyancy. This mechanically driven turbulence generated by the increased wind speed may be indirectly responsible for the increase in $\mathrm{C}_{\mathrm{T}}^{2}$ parameter during the monsoon season.
During the initial phase of the monsoon season an increase in wind speed is observed for both the years 2007 and 2008. Wind speed is nearly doubled for a long period which also masked the day-to-day variations of wind parameter. Further, lower heights have shown less variation than upper heights. The less variability observed in the lower height can be attributed to the complex terrain surrounding this site. The hills surrounding the SODAR in the area of $1 \mathrm{~km}$ radius are in the height range of 200-300 $\mathrm{m}$ and these hills perturb the basic wind flows. Magnitude of wind speed is nearly twice in the higher altitudes compared to the lower altitudes during the initial phase of southwest monsoon season. Increase in wind speed may also induce errors in $\mathrm{C}_{\mathrm{T}}^{2}$ measurements due to beam broadening effects. However, this SODAR system has a very narrow beam width of $5^{\circ}$ which minimizes the errors of beam broadening and hence can be neglected.

Figure 4 shows the variations in the monthly averaged vertical wind shear in horizontal for the observation period (a) 2007 and (b) 2008, respectively. Wind shear is observed to be minimum in April and May in both the years and is observed to be high during the months of June and July. During summer months maximum vertical shear in horizontal is around $0.015 \mathrm{~ms}^{-1} / \mathrm{m}$, whereas during monsoon months it is increased to $0.03 \mathrm{~ms}^{-1} / \mathrm{m}$. This increase in vertical wind shear component is attributed as a major source for the enhancement in the $\mathrm{C}_{\mathrm{T}}^{2}$ magnitude. During the month of April turbulence is generated only by strong heating process (thermal/buoyancy) with low winds observed over the station. With the arrival of the monsoon season, wind speeds are observed to be almost doubled in the lower ABL. This increase in wind speed generated wind shear which gave raise to mechanically generated turbulence along with thermal heating. Two peaks are observed in the lower layers; one around $75 \mathrm{~m}$ and the other at $200 \mathrm{~m}$. Lower peak in the shear is attributed due to the exchange between surface layer and mixed layer. Second peak in the wind shear plots around the $200 \mathrm{~m}$ height, may be due to surface complexity, i.e., hills nearby the SODAR are exactly in this range. The interaction of the hilltop with wind flow might be responsible for the generation of the second peak. $\mathrm{C}_{\mathrm{T}}^{2}$ decreases as wind shear decreases with height and it follows a similar trend.

\section{Conclusion}

Behaviour of the temperature structure parameter and wind information from Doppler SODAR measurements have been investigated over a tropical Indian station Gadanki during April-July for the 
years 2007 and 2008. The profiles of $\mathrm{C}_{\mathrm{T}}^{2}$ have shown increasing trend during the monsoon season. An increase in the westerly wind component $>8 \mathrm{~ms}^{-1}$ is observed during the early monsoon season. Magnitude of wind speed is almost found doubled with the arrival of monsoon. Vertical wind shear in horizontal component increased from $0.015 \mathrm{~ms}^{-1} / \mathrm{m}$ in summer months to $0.03 \mathrm{~ms}^{-1} / \mathrm{m}$ in monsoon months. Increase in $\mathrm{C}_{\mathrm{T}}^{2}$ during monsoon season is mainly due to the increase of vertical wind shear in horizontal and increased zonal wind component. Hence, mechanically generated turbulence dominated to moderate the values of $\mathrm{C}_{\mathrm{T}}^{2}$ over thermal perturbation/buoyancy during the monsoon season. Also it is observed that, southwest monsoon wind modulates the day-to-day variation of wind pattern during the initial phase of the monsoon season over this station. Temperature structure parameter is an important parameter for the turbulence studies which affects various transport mechanisms in the ABL. It is suggested that, the impact of mechanical turbulence on $\mathrm{C}_{\mathrm{T}}^{2}$ needs to be incorporated in the planetary boundary layer parameterization.

\section{References}

Anandan V K, Shravan Kumar M and Srinivasa Rao I 2008 First results of experimental tests of newly developed NARL phased array Doppler Sodar; J. Atmos. Oceanic Technol. 25(10) 1778-1784.

Asimakopoulos D N, Cole R S, Caughey S J and Crease B A 1976 A quantitative comparison between acoustic sounder returns and the direct measurement of atmospheric fluctuations; Bound.-Layer Meteorol. $10137-$ 147.

Bufton J L 1973 Correlation of microthermal turbulence data with meteorological soundings in the troposphere; J. Atmos. Sci. 30 83-87.

Caughey S J and Readings C J 1974 Vertical component of turbulence in convective conditions; Adv. Geophys. Academic Press, 18a 125-130.

Caughey S J, Crease B A, Asimakopoulos D N and Cole R S 1978 Quantitative bistatic acoustic sounding of the atmospheric boundary layer; Quart. J. Roy. Meteorol. Soc. 109(431) 147-161.

Coulman G E 1973 Vertical profiles of small-scale temperature structure in the atmosphere; Bound.-Layer Meteorol. 4 169-177.

Coulter R L 1990 A case study of turbulence in the stable nocturnal boundary layer; Bound.-Layer Meteorol. 52 75-91.

Coulter R L and Wesely M L 1980 Estimates of surface heat flux from sodar and laser scintillation measurements in the unstable boundary layer; J. Appl. Meteorol. 19 1209-1222.
Cuijpers J W M and Kohsiek W 1989 Vertical profiles of the structure parameter of temperature in the stable, nocturnal boundary layer; Bound.-Layer Meteorol. 47 111-129.

Derr V E and Little C G 1970 A comparison of remote sensing of the clear atmosphere by optical, radio, acoustical radar techniques; Appl. Opt. 9 1976-1992.

Dubosclard G 1982 A sodar study of the temperature structure parameter in the convective boundary layer; Bound.-Layer Meteorol. 22 325-334.

Gaynor J E 1977 Acoustic Doppler measurements of atmospheric boundary layer velocity structure functions and energy dissipation rates; J. Appl. Meteorol. 16 $148-155$.

Haugen D A and Kaimal J C 1978 Measuring temperature structure parameter profiles with an acoustic sounder; $J$. Appl. Meteorol. 17 895-899.

Helmis C G, Kalgiros J A, Asimakopoulos D N and Soilemes A T 2000 Estimation of potential-temperature gradient in turbulent stable layers using acoustic sounder measurements; Quart J. Roy. Meteorol. Soc. 126 31-61.

Kaimal J C, Wyngaard J C, Haugen D A, Rote O, Izumi Y, Caughey S J and Readings C J 1976 Turbulence structure in the convective boundary layer; J. Atmos. Sci. $332152-$ 2169.

Koprov B M 1965 Spectra of turbulent pulsations in the wind velocity in the boundary layer of the atmosphere under convective conditions; Izv. Atmos. Oceanic Phys. 1 1151-1159.

Little C G 1969 Acoustic methods for the remote sensing of the lower atmosphere; Proc. IEEE 57 571-578.

Moulsley T J, Asimakopoulos D N, Cole R S, Crease B A and Caughey S J 1981 Measurement of boundary layer structure parameter profiles by acoustic sounding and comparison with direct measurements; Quart. J. Roy. Meteorol. Soc. 107 203-230.

Neff W D 1975 Quantitative evaluation of acoustic echoes from the planetary boundary layer; NOAA Tech. Rep. ERL 322-WPL, 38, Boulder, 34pp.

Singhal S P, Gera B S and Agarwal S K 1982 Determination of structure parameters using sodar; Bound.-Layer Meteorol. 23 105-114.

Thomson D W, Coulter R L and Warhaft Z 1978 Simultaneous measurements of turbulence in the lower atmosphere using sodar and aircraft; J. Appl. Meteorol. 17 $723-734$.

Tsvang L R 1963 Some characteristics of the spectra of temperature pulsations in the boundary layer of the atmosphere; Bull. Acad. Sci. USSR Geophys. Ser. 10 1594-1600.

Warhaft Z 1973 The relation between temperature and humidity in the free atmosphere under conditions of stable stratification and strong thermal intermittency; Quart. J. Roy. Meteorol. Soc. 99 82-89.

Warner J 1972 The structure and intensity of turbulence in air over the sea; Quart. J. Roy. Meteorol. Soc. 98 175186.

Weill A, Aubry M, Baudin F and Heissat J 1976 A study on the temperature fluctuations in the atmospheric boundary layer; Bound.-Layer Meteorol. 10 337-346.

Weill A, Klapisz C, Strauss B, Baudin F, Jaupart C, Van Grundebeeck P and Goutorbe J P 1980 Measuring heat flux and structure functions of temperature fluctuations with an acoustic Doppler sodar; J. Appl. Meteorol. 19 199-205. 